\title{
Cancer caecum
}

\section{Cancer caecum}

Cancer Caecum is not an un common disease. The symptoms are non specific except Anaemia, thus it is ignored. Any patient with appendicular mass or having persistent drain after Appendectomy cancer of caecum should be suspected. Out of all colorectal cancers cancer caecum is second common cause after sigmoid colon and Rectal carcinoma. Due to the location the symptoms differ as compared with other colon malignancy (Figures 1-3).

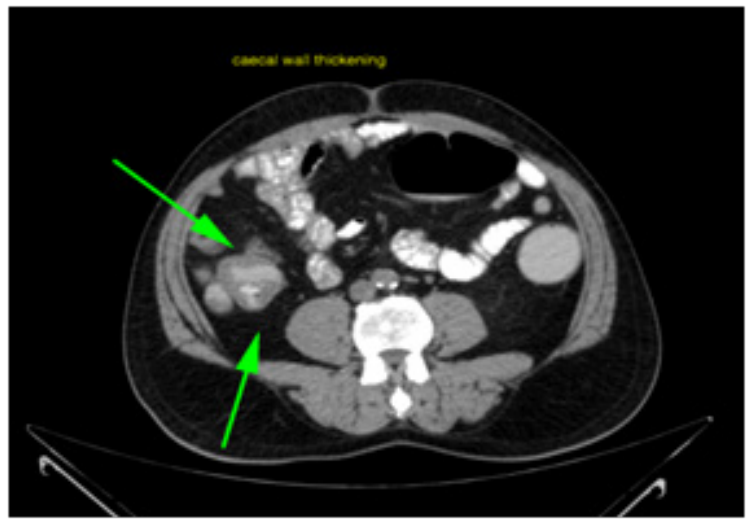

Figure I Caecal wall thickening.

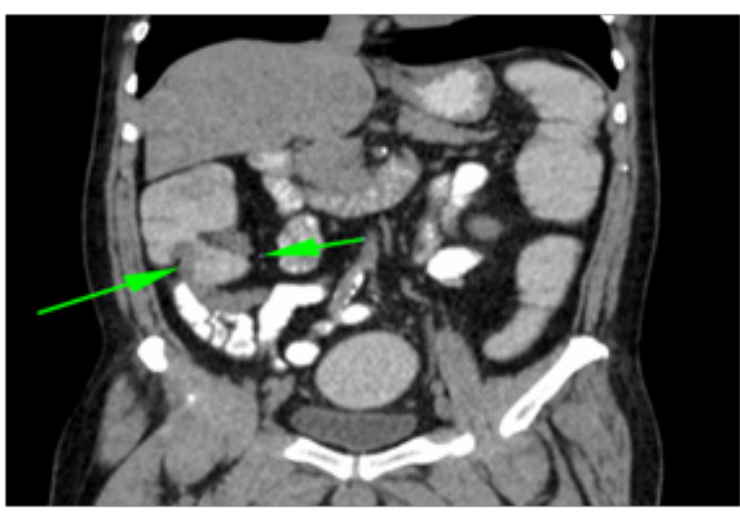

Figure 2 Caecal carcinoma.

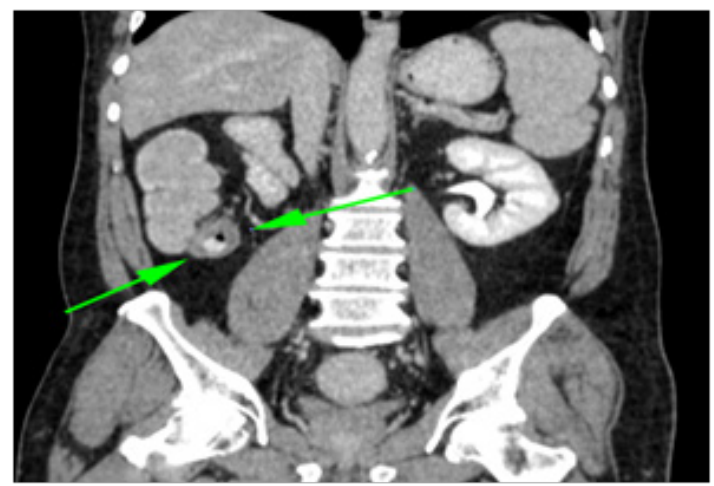

Figure 3 Caecal carcinoma.
Volume 4 Issue 4 - 2017

\section{Jayesh V Trivedi \\ Head of Department and Professor of Medicine, Gujarat Adani Institute of Medical Science, India}

\section{Correspondence: Jayesh V Trivedi, Head of Department} and Professor of Medicine, Gujarat Adani Institute of Medica Science, Bhuj, Gujarat, India, Email drjvtrivedi@rediffmail.com

Received: June 12, 2017 | Published: July 07, 2017

\section{Symptoms}

i. Many times it is asymptomatic.

ii. But sometimes symptoms may be Anaemia, abdominal pain, constipation, weight loss, vomiting. Intestinal obstruction is unusual.

iii. Persistent drain after appendectomy should raise the suspicion of malignancy.

iv. Adenocarcinoma and carcinoid tumours are common cancers in this area.

v. 5Years Survival rate is good $33 \%$ after surgery.

vi. Blood loss is usually occur but it may be huge blood loss in few cases.

vii. Perforation is a rare complication.

viii. Right hemicolectomy or ileotranversotomy with resection of abdominal wall is the treatment of choice in such cases.

ix. Resections of iliac nodes can be carried out if it is involved. ${ }^{1-3}$

\section{Acknowledgements}

None.

\section{Conflict of interest}

The author declares no conflict of interest.

\section{References}

1. Bowel cancer (adenocarcinoma of the caecum) my VMC; 2002.

2. Caecal carcinoma-General Practice Notebook, UK

3. Symptoms of Cecum Carcinoma, Livestrong.Com. 